\title{
HUBUNGAN TINGKAT PENGETAHUAN DANDUKUNGAN KELUARGA TERHADAP KEPATUHAN DIET PASIEN DIABETES MELLITUS DI KLINIK BHAKTI HUSADA PURWAKARTA
}

\author{
Handayani ${ }^{1}$, Yanesti Nuravianda $\mathrm{L}^{2}$, Irwan Haryanto ${ }^{3}$ \\ ${ }^{1,2,3}$ Sekolah Tinggi Ilmu Kesehatan Holistik Purwakarta
}

\begin{abstract}
ABSTRAK
Latar belakang: Diabetes mellitus (DM) adalah keadaan hiperglikemi kronik yang disertai berbagai kelainan akibat gangguan hormonal yang menimbulkan berbagai komplikasi kronik pada mata, ginjal, saraf, dan pembuluh darah. Dukungan keluarga sangat penting untuk memotivasi pasien dalam menjalankan pengobatan ataupun diet diabetes mellitus.

Tujuan: Mengetahui hubungan pengetahuan dan dukungan keluarga terhadap kepatuhan diet DM pasien rawat jalan di klinik Bhakti Husada Purwakarta.

Metode: Penelitian ini merupakan jenis penelitian Observasional dengan desain cross sectional. Subjek penelitian adalah pasien DM di Klinik Bhakti Husada Purwakarta yang berjumlah 24 orang. Data yang dikumpulkan adalah tingkat pengetahuan, dukungan keluarga, dan kepatuhan diet. Data diperoleh melalui kuisioner. Analitik data menggunakan uji Chi-Square.

Hasil: Sebagian besartingkat pengetahuan responden tergolong kurang $(64,3 \%)$, dan dukungan keluarga responden terhadap kepatuhan menjalani terapi diet DM tipe 2 baik (50\%).Terdapathubungan antara pengetahuan dengan kepatuhan diet pasien DM $(\mathrm{p}=0,008)$, namun tidak ada hubungan antara dukungan keluarga dengan kepatuhan pasien DM ( $\mathrm{p}=0,408)$.
\end{abstract}

Kesimpulan: Ada hubungan antara pengetahuan dengan kepatuhan diet DM tipe 2.

KATA KUNCI: pengetahuan, dukungan keluarga, diabetes mellitus

Korespondensi :

Yanesti Nuravianda L

Program Studi Ilmu Gizi, STIKes Holistik Purwakarta

J1. Veteran No. 272 Ciseureuh Purwakarta, Jawa Barat 41118

Email : yanestinur.al@gmail.com

Phone : 0857-9119-7147 


\title{
THE CORRELATION OF KNOWLEDGE AND FAMILY SUPPORT ON THE DIET COMPLIANCE OF DIABETES MELLITUS PATIENTS IN BHAKTI HUSADA CLINIC PURWAKARTA
}

\begin{abstract}
Background: Diabetes mellitus (DM) is a state of chronic hyperglycemia accompanied by various disorders due to hormonal disturbances that cause a variety of chronic complications in the eyes, kidneys, nerves, and blood vessels. Family support is very important to motivate patients in performing the treatment of diabetes mellitus or diet.

Objective: To examine the relationship of knowledge and family support for diet adherence DM outpatient clinic Bhakti Husada Purwakarta.

Methods: This study is observational research with cross sectional design. Subjects were patients with DM Clinic Bhakti Husada Purwakarta amounting to 24 people. The data collected is the level of knowledge, family support, and dietary compliance. Data obtained through questionnaires. Analytical data using Chi-Square test.

Results: The majority of respondents' knowledge level was classified as less (64.3\%), and family support respondents to compliance in therapy of type 2 diabetes diet is good (50\%). There is a relationship between knowledge and adherence diet DM patients $(\mathrm{p}=0.008)$, but there is no relationship between family support compliance DM patients $(\mathrm{p}=0.408)$.

Conclusion: There is a relationship between knowledge with type 2 diabetes diet adherence.
\end{abstract}

KEYWORDS: knowledge, family support, diabetes mellitus 


\section{PENDAHULUAN}

Diabetes Mellitus

(DM)

merupakan kelainan degeneratif, yang umumnya disertai dengan adanya hiperrglikemia dan intoleransi glukosa akibat defisiensi insulin dan atau resistensi insulin. Berdasarkan etiologi dan gejala klinis, DM dapat dikategorikan menjadi 4 (empat) tipe antara lain DM tipe 1, DM tipe 2, Gestational Diabetes dan tipe spesifik lainnya. ${ }^{1}$

Berdasarkan hasil estimasi International Diabetes Federation (IDF), prevalensi global penderita diabetes pada tahun 2013 sebanyak 328 juta jiwa dan diduga akan meningkat menjadi 592 juta pada tahun 2035. ${ }^{2}$ Prevalensi penderita DM pada usia 20-79 tahun pada tahun 2010 sebesar $6,4 \%$ penduduk dunia dan akan meningkat menjadi 7,7\% pada tahun 2030. Antara tahun 2010-2030 akan terjadi peningkatan sebesar $69 \%$ penderita diabetes di negara sedang berkembang dan 20\% di negara maju. ${ }^{3}$ Perkembangan hasil penelitian tentang prevalensi penderita DM juga mengindikasikan bahwa lebih dari $60 \%$ populasi penduduk di dunia yang menderita
DM berasal dari negara-negara di kawasan Asia. ${ }^{4}$

Indonesia merupakan negara keempat yang memiliki jumlah penderita DM terbanyak di dunia. Pada tahun 2006, jumlah penderita diabetes diperkirakan mencapai 14 juta orang, dan hanya 50\% yang menyadari kondisi tersebut serta sekitar $30 \%$ yang datang berobat secara teratur. ${ }^{5}$ Berdasarkan Riset Kesehatan Dasar (Riskesdas) tahun 2013, prevalensi DM di Indonesia sebesar 1,5\%. Menurut hasil penelitian yang dilakukan oleh DiabCare di Indonesia, diketahui bahwa 47,2\% memiliki kendali yang buruk pada gula darah plasma puasa $>130 \mathrm{mg} / \mathrm{dl}$ pada penderita DM tipe 2.6

Adapun pengelolaan DM meliputi 4 pilar utama yang terdiri dari perencanaan diet, terapi farmakologis berupa obat-obatan anti diabetes atau injeksi insulin, pengaturan aktivitas fisik dan olahraga serta pemberian edukasi. Intervensi perencanaan diet merupakan pengelolaan diabetes yang paling utama karena dapat membantu mengontrol kadar gula darah. Perencanaan menu makanan 
yang tepat akan membantu memperbaiki pola makan penderita diabetes sehingga kadar gula darah akan lebih terkendali. Keberhasilan perencanaan makan sangat tergantung dengan kepatuhan penderita diabetes dalam menjalani anjuran makan yang diberikan. Namun kepatuhan menjalani anjuran makan justru menjadi tantangan yang berat dalam melaksanakan diet bagi penderita diabetes.Pengendalian jumlah kalori, pengaturan porsi dan jenis makanan yang dikonsumsi cenderung membingungkan dan sulit diikuti. Kendala lainnya terkait dengan adanya kejenuhan penderita diabetes dalam mengikuti pengaturan makan yang telah dianjurkan. Hal ini dapat dikaitkan dengan keterbatasan pengetahuan terkait pengaturan porsi dan jenis makanan bagi penderita diabetes. Selain itu dibutuhkan pula dukungan penuh dari keluarga sehingga penderita diabetes tetap patuh melaksanakan anjuran diet.

Hasil penelitian tahun 2013 pada pasien DM di ruang rawat inap RS. Baptis, Kediri menyatakan bahwa dari 25 orang responden, $68 \%$ responden memiliki dukungan keluarga yang baik dan sebanyak $80 \%$ responden menunjukkan kepatuhan terhadap terapi diet karena adanya dukungan keluarga yang baik tersebut. Penelitian ini juga membuktikan bahwa dukungan keluarga mampu meningkatkan kepatuhan diet pasien $\mathrm{DM}^{7}$ Berdasarkan penelitian lainnya pada tahun 2013 terhadap 30 responden di wilayah Puskesmas Pakis, Surabaya diperoleh hasil bahwa faktor pengetahuan mempengaruhi kepatuhan diet sebesar 29 orang (97,\%), faktor sikap mempengaruhi sebesar 28 orang $(93,3 \%)$, faktor dukungan keluarga mempengaruhi sebesar 30 orang (100\%). Faktor yang paling mempengaruhi adalah faktor dukungan keluarga sebesar 30 orang (100\%). Hal ini menunjukkan bahwa peran keluarga sangat besar dalam pelaksanaan kepatuhan diet bagi penderita $\mathrm{DM}^{8}{ }^{8}$ Penelitian lain pada 64 responden di wilayah Puskesmas Plosorejo Giribangun Matesih Kabupaten Karanganyar menyatakan bahwa terdapat hubungan signifikan antara pendidikan dan dukungan keluarga 
terhadap kepatuhan diet pada penderita DM. ${ }^{9}$

Berdasarkan data awal yang didapatkan dari register, DM tipe 2 di Klinik Bhakti Husada, pada bulan april 2016 jumlah penderita DM tipe 2 sebanyak 50 orang. Sebagian besar pasien dirujuk ke Rumah Sakit karena sebagian pasien secara penilaian fisik sudah tidak mampu untuk pergi ke Klinik, rata-rata pasien ke Rumah sakit hanya untuk menyambung obat.Oleh karena itu penelitian ini bertujuan untuk mengetahui hubungan antara tingkat pengetahuan dan dukungan keluarga terhadap perilaku kepatuhan diet penderita DM tipe 2 di Klinik Bhakti Purwakarta.

\section{METODE}

\section{Jenis dan Rancangan Penelitian}

Penelitian yang menggunakan metode observasional dengan pendekatan cross sectionalini dilaksanakan di Klinik Bhakti Husada, Purwakarta pada bulan Juli Agustus 2016. Penelitian ini mengkaji tingkat pengetahuan pasien dan dukungan keluarga dan dikaitkan dengan kepatuhan diet pasien DM tipe 2 .

\section{Subyek Penelitian}

Subyek penelitian ini adalah pasien rawat jalan di Klinik Bhakti Husada, Purwakarta yang memenuhi kriteria inklusi antara lain merupakan pasien yang tediagnosa oleh dokter menderita DM tipe 2; pasien berkunjung ke Klinik Bhakti Husada selama periode bulan Juli-Agustus 2016; melakukan kontrol/check-up kadar glukosa darah rutin setiap bulan; penyakit DM tipe 2 tanpa komplikasi atau dengan komplikasi hipertensi atau asam urat; dan bersedia menjadi subyek penelitian serta kriteria eksklusi antara lain pasien terdiagnosa DM tipe 1; tidak pernah melakukan kontrol gula darah; memiliki komplikasi berat atau multi-komplikasi (jantung, ginjal, kanker dan atau gangren) dan atau dirujuk ke rumah sakit untuk rawat inap.Subyek penelitian diambil menggunakan teknik purposive sampling sebanyak 24 orang. ${ }^{10,11}$

\section{Tingkat Pengetahuan}

Tingkat pengetahuan diperoleh berdasarkan kemampuan 
subyek penelitian dalam menjawab pertanyaan tentang diet penyakit DM tipe 2. Terdapat 21 butir pertanyaanbeserta alternatif pilihan jawaban yang disajikan dalam kuesioner (17 butir pertanyaan positif dan 4 pertanyaan negatif).Adapun tingkat pengetahuansubyek penelitian dinilai menggunakan skala Guttman, melalui penetapan bobot untuk setiap item jawaban, skor 1 (satu) bila jawaban benar dan skor 0 (nol) bila jawaban salah.Semakin tinggi skor semakin baik tingkat pengetahuan subyek penelitian. Seluruh jawaban kemudian dijumlahkan dan dikategorikan menjadi 2 (dua) kategori yaitu tingkat pengetahuan baik dan kurang.

\section{Dukungan Keluarga}

Dukungan keluarga dinilai menggunakan kuesioner yang diadopsi dari Hensarling Diabetes Family Support Scale (HDFSS) yang dikembangkan oleh Hensarling dan telah digunakan pada penelitian sebelumnya. Kuesioner ini terdiri dari 29 item pernyataan dengan alternatif jawaban menggunakan skala likertantara 1-4 (4=selalu; $3=$ sering; $2=$ jarang; $1=$ tidak pernah untuk pernyataan positif dan 1=selalu; $\quad 2=$ sering; $\quad 3=$ jarang; 4=tidak pernah untuk pernyataan negatif). Dimensi dukungan keluarga yang dinilai meliputi dimensi emosional, penghargaan, instrumental, dan informasi. ${ }^{12}$ Jumlah skor kumulatif jawaban kemudian dibagi dengan total item pernyataan.Semakin tinggi skor berarti semakin tinggi dukungan keluarga yang dirasakan.Dukungan keluarga kemudian dikategorikan menjadi 2 (dua) kategori yaitu baik dan kurang.

Kepatuhan Diet Pasien DM tipe 2

Kepatuhan diet dinilai menggunakan kuesioner yang terdiri dari 18 item pernyataan dengan alternatif jawaban menggunakan skala likert antara 1-4 (4=selalu; $3=$ sering; $2=$ jarang; $1=$ tidak pernah untuk penryataan positif dan 1=selalu; $\quad 2=$ sering; $\quad 3=$ jarang; 4=tidak pernah untuk pernyataan negatif). Kuesioner berisi pernyataan tentang sikap taat dan patuh dalam menjalankan terapi diet sesuai dengan jenis, jumlah, dan jadwal makan yang dianjurkan. Jumlah skor kumulatif jawaban kemudian dibagi 
dengan total item pernyataan.Kepatuhan diet pasien DM tipe 2 kemudian dikategorikan menjadi 2 (dua) kategori yaitu patuh dan tidak patuh.

\section{HASIL PENELITIAN}

\section{Analisis Data}

$$
\text { Data hasil penelitian }
$$
dianalisis menggunakan SPSS 16.0 for windows.Data karakteristik subyek penelitian berdasarkan demografi, tingkat pengetahuan, dukungan keluarga dan kepatuhan diet pasien DM tipe 2 dianalisis secara deskriptif dan disajikan dalam bentuk tabel. Data kepatuhan diet pasien DM tipe 2 berdasarkan tingkat

Hasil penelitian menunjukkan bahwa sebagian besar pasien DM tipe 2 rawat jalan di Klinik Bhakti Husada, Purwakarta yang menjadi subyek penelitian adalah perempuan $(62,5 \%)$, berusia $>30$ tahun $(87,5 \%)$ dan bekerja sebagai ibu rumah tangga $(37,5 \%)$. Sebagian besar subyek penelitian memiliki pendidikan terakhir tamat SMA $(45,8 \%)$.

Tabel 1. Gambaran Karakteristik Pasien Diabetes Mellitus Rawat Jalan di Klinik Bhakti Husada, Purwakarta

\begin{tabular}{|c|c|c|c|c|c|c|c|}
\hline \multirow{3}{*}{ No. } & \multirow{3}{*}{ Karakteristik } & \multicolumn{4}{|c|}{ Kepatuhan Diet Pasien } & \multirow{2}{*}{\multicolumn{2}{|c|}{ Jumlah }} \\
\hline & & \multicolumn{2}{|c|}{ Patuh } & \multicolumn{2}{|c|}{ Tidak patuh } & & \\
\hline & & $\mathbf{n}$ & $\%$ & $\mathbf{n}$ & $\%$ & $\mathbf{n}$ & $\%$ \\
\hline \multirow[t]{3}{*}{1} & Jenis Kelamin & & & & & & \\
\hline & a. Laki-Laki & 5 & $20,8 \%$ & 4 & $16,7 \%$ & 9 & 37,5 \\
\hline & b. Perempuan & 9 & $37,5 \%$ & 6 & $25,0 \%$ & 15 & 62,5 \\
\hline \multirow[t]{3}{*}{2} & Umur & & & & & & \\
\hline & a. $25-30$ thn & 1 & $4,2 \%$ & 2 & $8,3 \%$ & 3 & 12,5 \\
\hline & b. $>30$ thn & 11 & $45,8 \%$ & 10 & $41,7 \%$ & 21 & 87,5 \\
\hline \multirow[t]{6}{*}{3} & Pendidikan & & & & & & \\
\hline & a. Tidak Sekolah & 1 & $4,2 \%$ & 1 & $4,2 \%$ & 2 & 8,3 \\
\hline & b. SD & 2 & $8,3 \%$ & 1 & $4,2 \%$ & 3 & 12,5 \\
\hline & c. SMP & 2 & $8,3 \%$ & 3 & $12,5 \%$ & 5 & 20,8 \\
\hline & d. SMA & 7 & $29,1 \%$ & 4 & $16,7 \%$ & 11 & 45,8 \\
\hline & e. PT & 2 & $8,3 \%$ & 1 & $4,2 \%$ & 3 & 12,5 \\
\hline \multirow[t]{5}{*}{4} & Pekerjaan Sebelum Sakit & & & & & & \\
\hline & a. Swasta & 1 & $4,2 \%$ & 6 & $25,0 \%$ & 7 & 29,2 \\
\hline & b. Wiraswasta & 3 & $12,5 \%$ & 2 & $8,3 \%$ & 5 & 20,8 \\
\hline & c. PNS & 2 & $8,3 \%$ & 1 & $4,2 \%$ & 3 & 12,5 \\
\hline & d. IRT & 8 & $33,3 \%$ & 1 & $4,2 \%$ & 9 & 37,5 \\
\hline \multirow[t]{2}{*}{5} & Status Perkawinan & & & & & & \\
\hline & a. Kawin & 11 & $45,8 \%$ & 8 & $33,3 \%$ & 19 & 79,2 \\
\hline
\end{tabular}




\begin{tabular}{|c|c|c|c|c|c|c|c|}
\hline \multirow{3}{*}{ No. } & \multirow{3}{*}{ Karakteristik } & \multicolumn{4}{|c|}{ Kepatuhan Diet Pasien } & \multirow{2}{*}{\multicolumn{2}{|c|}{ Jumlah }} \\
\hline & & \multicolumn{2}{|c|}{ Patuh } & \multicolumn{2}{|c|}{ Tidak patuh } & & \\
\hline & & $\mathbf{n}$ & $\%$ & $\mathbf{n}$ & $\%$ & $\mathbf{n}$ & $\%$ \\
\hline & b. Duda/Janda & 3 & $12,5 \%$ & 2 & $8,3 \%$ & 5 & 20,8 \\
\hline \multirow[t]{4}{*}{6} & Lama Menderita DM & & & & & & \\
\hline & a. $\quad<1$ thn & 4 & $16,7 \%$ & 4 & $16,6 \%$ & 8 & 33,3 \\
\hline & b. $1-10$ thn & 7 & $29,2 \%$ & 5 & $20,8 \%$ & 12 & 50,0 \\
\hline & c. $>10$ thn & 3 & $12,5 \%$ & 1 & $4,2 \%$ & 4 & 16,7 \\
\hline \multirow[t]{5}{*}{7} & Sumber Informasi Diet DM & & & & & & \\
\hline & a. Tidak ada & 2 & $4,2 \%$ & 0 & $0,0 \%$ & 2 & 8,3 \\
\hline & b. Keluarga & 3 & $12,5 \%$ & 0 & $0,0 \%$ & 3 & 12,5 \\
\hline & c. Tenaga Kesehatan & 7 & $29,1 \%$ & 10 & $41,7 \%$ & 17 & 70,8 \\
\hline & d. Media Elektronik & 2 & $8,3 \%$ & 0 & $0,0 \%$ & 2 & 8,3 \\
\hline
\end{tabular}

Sebanyak 50 persen subyek penelitian telah menderita penyakit DM tipe 2 antara $1-10$ tahun. Adapun subyek penelitian mengutarakan bahwa sumber informasi terkait diet DM tipe 2 lebih banyak diperoleh melalui tenaga kesehatan $(70,8 \%)$. Karakteristik subyek penelitian secara lengkap disajikan dalam Tabel 1.

\section{Hubungan Tingkat Pengetahuan} terhadapKepatuhan Diet Pasien DM Tipe 2

Hasil analisis menggunakan Chi-Squaremenunjukkan bahwa tingkat pengetahuan menunjukkan hubungan yang signifikan terhadap kepatuhan diet subyek penelitian yang menderita DM tipe 2 yang ditunjukkan dengan nilai $\mathrm{p}<0,05$ $(\mathrm{p}=0,008)$. Hasil analisis juga menyatakan bahwa prevalence ratio tingkat pengetahuan terhadap kepatuhan diet menunjukkan nilai 0,34 . Hal ini berarti bahwa tingkat pengetahuan merupakan faktor proteksi terhadap kepatuhan diet subyek penelitian yang menderita DM tipe 2.Hasil analisis secara lengkap disajikan pada Tabel 2.

Tabel 2.Hubungan Tingkat Pengetahuan terhadapKepatuhan Diet Pasien DMTipe 2 di Klinik Bhakti Husada, Purwakarta

\begin{tabular}{|c|c|c|c|c|c|c|}
\hline \multirow{3}{*}{ Tingkat Pengetahuan } & \multicolumn{4}{|c|}{ Kepatuhan Diet Pasien } & \multirow{3}{*}{ Nilai P } & \multirow{3}{*}{ PR } \\
\hline & \multicolumn{2}{|c|}{ Patuh } & \multicolumn{2}{|c|}{ Tidak Patuh } & & \\
\hline & $\mathbf{n}$ & $\%$ & $\mathbf{n}$ & $\%$ & & \\
\hline Baik & 5 & $35,7 \%$ & 9 & $64,3 \%$ & \multirow{2}{*}{0,008} & \multirow{2}{*}{0,34} \\
\hline Kurang & 9 & $64,3 \%$ & 1 & $10,0 \%$ & & \\
\hline
\end{tabular}

Hubungan Dukungan Keluarga terhadap Kepatuhan Diet DM
Hasil analisis menggunakan Chi-Square menunjukkan bahwa 
dukungan keluarga tidak nilai $\mathrm{p} \geq 0,05 \quad(\mathrm{p}=0,408)$. Hasil berhubungan dengan kepatuhan diet analisis secara legkap disajikan pada subyek penelitian yang menderita Tabel 3.

DM tipe 2 yang ditunjukkan dengan

Tabel 3. Hubungan Dukungan Keluarga dengan Kepatuhan Diet Pasien DM Tipe 2 di Klinik Bhakti Husada, Purwakarta

\begin{tabular}{lccccc}
\hline \multirow{2}{*}{ Dukungan keluarga } & \multicolumn{3}{c}{ Kepatuhan Diet Pasien } & \multirow{2}{*}{ Nilai P } \\
\cline { 2 - 5 } & \multicolumn{2}{c}{ Patuh } & \multicolumn{2}{c}{ Tidak patuh } & \\
\cline { 2 - 5 } & $\mathbf{n}$ & $\mathbf{\%}$ & $\mathbf{n}$ & $\boldsymbol{\%}$ & \\
\hline Baik & 6 & $42,9 \%$ & 6 & $60,0 \%$ & \multirow{2}{*}{0,408} \\
Kurang & 8 & $57,1 \%$ & 4 & $40,0 \%$ & \\
\hline
\end{tabular}

\section{PEMBAHASAN}

Hubungan Tingkat Pengetahuan

terhadapKepatuhan Diet Pasien DM

Tipe 2

Hasil penelitian menyatakan bahwa tingkat pengetahuan subyek penelitian terhadap diet penyakit DM berhubungan dengan kepatuhan dalam melaksanakan diet.Penelitian ini juga menunjukkan bahwa semakin baik tingkat pengetahuan terhadap diet penyakit DM maka subyek penelitian menjadi semakin patuh dalam menjalankan dietnya. Hal ini dikaitkan dengan adanya pemahaman khususnya pengetahuan tentang penatalaksanaan nutrisi penderita DM tipe 2 sehingga akan membuat seseorang menjadi lebih waspada dan berhati-hati dalam memilih makanan yang akan dikonsumsi, dan pada akhirnya akan terbentuk suatu perilaku patuh terhadap diet yang dijalani. Hal ini dapat pula diartikan bahwa semakin baik tingkat pengetahuan seseorang tentu akan semakin banyak paparan informasi yang diperoleh. Semakin banyak dan semakin sering paparan informasi tersebut diperoleh maka akan mempengaruhi sikap dan perilaku seseorang dalam melakukan sesuatu.

Penelitian ini didukung dengan hasil penelitian sebelumnya yang dilakukan tahun 2011 pada 200 orang pasien DM di Polandia. Penelitian tersebut mengkaji tentang kepatuhan pasien diabetes mellitus terhadap monitoring kadar gula darah dan terapi medis. Penelitian tersebut menyatakan bahwa terdapat 
hubungan antara pengetahuan terhadap kepatuhan pasien dalam menjalankan terapi obat. Dalam penelitian tersebut juga dijelaskan bahwa pengetahuan sangat diperlukan agar terbentuk tindakan atau perilaku positif yang berlangsung lama. ${ }^{13}$ Hasil penelitian ini juga didukung dengan penelitian lain yang dilakukan tahun 2013 pada 69 orang pasien poliklinik RSUD Kota Tidore Kepulauan Provinsi Maluku Utara yang mengkaji tentang hubungan antara pengetahuan dan dukungan keluarga dengan kepatuhan menjalani diet diabetes mellitus. Penelitian tersebut menyatakan baha terdapat hubungan antara pengetahuan dengan kepatuhan menjalani diet diabetes melitus $(p=0,023) .{ }^{14} \mathrm{Di}$ sisi lain, hasil penelitian ini menunjukkan perbedaan dengan hasil penelitian yang diakukan di Puskesmas Kasihan II Bantul, Yogyakarta yang menyatakan bahwa pengetahuan tidak berhubungan dengan kepatuhan dalam menjalani diet diabetes mellitus tipe $2(p=0,537){ }^{15}$

\section{Hubungan Dukungan Keluarga} terhadap Kepatuhan Diet DM
Hasil penelitian menyatakan bahwa dukungan keluarga tidak berhubungan dengan kepatuhan subyek penelitian dalam menjalankan diet DM. Hal ini sejalan dengan penelitian sebelumya yang dilakukan tahun 2015 pada 68 orang penderita diabetes mellitus tipe $2 \mathrm{di}$ Puskesmas Kasihan II Bantul Yogyakarta. Penelitian tersebut menyatakan bahwa dukungan keluarga tidak berhubungan dengan kepatuhan dalam menjalani diet diabetes mellitus tipe 2 $(\mathrm{p}=0,937) .{ }^{15} \mathrm{Hal}$ ini dikaitkan dengan adanya dominasi faktor internal yaitu motivasi diri terhadap kepatuhan dalam menjalankan diet diabetes mellitus yang diberikan. Dukungan keluarga yang baik tidak akan berhasil merubah dan mempengaruhi perilaku seseorang jika tidak diikuti dengan adanya kesadaran dari diri seseorang tersebut untuk melakukan tindakan. Namun, dukungan keluarga menjadi faktor yang sangat penting dalam memotivasi pasien dalam menjalankan pengobatan maupun terapi diet yang diberikan. Keterlibatan keluarga sejak awal diagnosis penyakit seorang pasien 
merupakan langkah yang harus ditempuh untuk memberi dukungan pada pasien dan akan berdampak positif terhadap kelangsungan pengobatan. Di sisi lain, penelitian ini berbeda dengan hasil penelitian sebelumnya yang dilakukan tahun 2014 pada 60 orang pasien DM di Puskesmas Srondol Kecamatan Banyumanik Semarang yang menyatakan bahwa terdapat hubungan yang signifikan antara pengetahuan dan dukungan keluarga dengan kepatuhan penderita DM ( $p=0,016$ dan 0,034).

\section{SIMPULAN}

Dapat disimpulkan bahwa bahwa semakin baik tingkat pengetahuan terhadap diet penyakit DM maka subyek penelitian menjadi semakin patuh dalam menjalankan dietnya.Namun, semakin baik dukungan keluarga belum tentu meningkatkan kepatuhan pasien DM tipe 2 dalam menjalankan diet.

\section{DAFTAR PUSTAKA}

1. Sicree, R., Shaw, J., and Zimmet P. The Global Burden.Diabetes and Impaired Glucose
Tolerance. Prevalence and Projection. IDFDiabetes Atlas $4^{\text {th }} \quad$ Edition. Brussels :International Diabetes Federation; 2009.

2. Forouhi G., N., Wareham, N., J. Epidemiology of Diabetes. 2014; 42 (12): 698-702.

3. Shaw J., Sicree, R.,Zimmet, P. Global Estimates of The Prevalence of Diabetes for 2010 and 2030. Diabetes Research and Clinical Practice. 2009; 87: 4-14.

4. Ramachandran A., Snehalatha C., Shetty A. S., Nanditha A. Trends in Prevalence of Diabetes in Asian Countries. World J Diabetes. 2012; 3(6):110-17.

5. World Health Organization. The Top 10 Causes of Death [online]. WHO. http://www.who.int/mediacentr e/factsheets/fs310/en/index.htm 1. 2011. [diakses 7 Juni 2012].

6. Soewondo, P., Soegondo, S., Suastika, K., Pranoto, A., Soeatmadji, D. W., Tjokroprawiro, A. The DiabCare Asia 2008 study - 
Outcomes on Control and

Complications of Type 2

Diabetic Patients in Indonesia.

Medical Journal of Indonesia. 2010; 19(4): 235-244.

7. Susanti, M. L., Sulistyarini, T. Dukungan Keluarga

Meningkatkan Kepatuhan Diet

Pasien Diabetes Mellitus di Ruang Rawat Inap RS. Baptis

Kediri. Jurnal STIKES. 2013; $6(1): 1-10$.

8. Fauzia Y., Sari E., Artini B. Gambaran Faktor-Faktor yang Mempengaruhi Kepatuhan Diet Penderita Diabetes Mellitus di Wilayah Puskesmas Pakis Surabaya. Jurnal AKPER William Booth. 2013: 1-7.

9. Prabowo, A., Hastuti, W. Hubungan Pendidikan dan Dukungan Keluarga dengan Kepatuhan Diit pada Penderita Diabetes Mellitus di Wilayah Puskesmas Plosorejo

Giribangun Matesih Kabupaten Karanganyar. Jurnal STIKes. 2014: 1-12.

10. Sastroasmoro $\mathrm{S}$, Ismael $\mathrm{S}$. Dasar-dasar metodologi penelitian klinis. Edisi 4.
Jakarta: CV Sagung Seto; 2011.

11. Notoatmodjo, S. Metodologi Penelitian Kesehatan. Jakarta: Rineka Cipta; 2012.

12. Yusra, A.Hubungan Antara Dukungan Keluarga Dengan Kualitas Hidup Pasien

Diabetes Melitus Tipe 2 Di Poliklinik Penyakit Dalam Rumah Sakit Umum Pusat Fatmawati Jakarta. Tesis. Magister Ilmu Keperawatan Kekhususan Keperawatan Medikal Bedah Fakultas Ilmu KeperawatanUniversitas Indonesia. 2011.

13. Kasznicki, Glowacka, Drzewoski. Type 2 Diabetic Patients Compliance with Drug Therapy and Glycaemic Control. Diabetologia Doswiadczalna i Kliniczna. 2011; 7(4):199-203.

14. Senuk, A., Supit, W., Onibala, F. Hubungan Pengetahuan dan Dukungan Keluarga dengan Kepatuhan Menjalani Diet Diabetes Melitus di Poliklinik Rsud Kota Tidore Kepulauan Provinsi Maluku Utara. 
Ejournal Keperawatan. 2013; 1(1): $1-7$.

15. Astuti, S., Paratmanitya, Y., Wahyuningsih. Tingkat pengetahuan dan dukungan keluarga tidak berhubungan dengan kepatuhan menjalani terapi diet penderita diabetes mellitus tipe 2 di Puskesmas Kasihan II Bantul Yogyakarta. Jurnal Gizi Dan Dietetik Indonesia. 2015; 3(2): 105-12.
16. Shofiyah, S., Kusuma, H. Hubungan Antara Pengetahuan Dan Dukungan Keluarga Terhadap Kepatuhan Penderita Diabetes Melitus (Dm) Dalam Penatalaksanaan Di Wilayah Kerja Puskesmas Srondol Kecamatan Banyumanik Semarang. Prosiding Konferensi Nasional II PPNI Jawa Tengah. 2014: 308-14. 